\title{
THE USE OF THIAFENTANIL OXALATE AND AZAPERONE FOR REVERSIBLE IMMOBILISATION OF AFRICAN BUFFALO (SYNCERUS CAFFER) WITHIN A NATURE RESERVE - SHORT COMMUNICATION
}

\author{
Zoltán SZABÓ $^{1 *+}$, Diederik Jacobus VENTER ${ }^{2+}$, Eustatius Du Chavoux LUYT ${ }^{3}$ \\ and Cobus RAATH ${ }^{2}$
}

${ }^{1}$ Tai Wai Small Animal and Exotic Hospital, 75 Chik Shun Street, Tai Wai, Shatin, New Territories, Hong Kong; ${ }^{2}$ Wildlifevets.com, Karino, South Africa;

${ }^{3}$ Stellenbosch University, Otjiwarongo, Namibia

(Received 12 September 2014; accepted 29 October 2014)

\begin{abstract}
Although thiafentanil oxalate has been widely used for wildlife immobilisation on different species, no report has been published about its usefulness on African buffalo (Syncerus caffer). Thirty-four African buffaloes were successfully immobilised at Loskop Dam Nature Reserve, South Africa in July 2013. The animals were kept in bomas of the nature reserve. The purpose of the immobilisation was to provide opportunity for microchip implantation, ear tag placement, intradermal tuberculin test and blood sampling. All animals were immobilised with thiafentanil oxalate $6 \mathrm{mg} / \mathrm{animal}(0.007-0.01 \mathrm{mg} / \mathrm{kg})$ and azaperone $40 \mathrm{mg} / \mathrm{animal}$ $(0.07-0.04 \mathrm{mg} / \mathrm{kg})$ using Dan-inject darts and gun. The opioid reversal agent naltrexone hydrochloride $60 \mathrm{mg} /$ animal $(0.07-0.1 \mathrm{mg} / \mathrm{kg})$ was given intravenously to the ear vein. The mean induction time was $3.9 \pm 0.2 \mathrm{~min}$, the recovery time was $1.65 \pm 0.87 \mathrm{~min}$. The results of the present study indicate that thiafentanil oxalate, this low-volume, high-potency, reversible drug combined with azaperone provides fast induction and smooth recovery. The authors recommend this drug combination as a reliable immobilising regimen for African buffalo.
\end{abstract}

Key words: Immobilisation, African buffalo, thiafentanil oxalate, naltrexone, azaperone

Short periods of chemical immobilisation of large wild mammals are often required for examination, blood sampling, microchip implantation, application of telemetry devices and transportation (Kreeger et al., 2002).

Thiafentanil oxalate is a potent $\mu$ receptor agonist opioid drug. It is 6,000 times more potent than morphine (West et al., 2008). Its potency is similar to that of etorphine hydrochloride, but its induction time and duration of effect are shorter (West et al., 2008). The potency and concentrated formulation of thiafen-

\footnotetext{
*Corresponding author; E-mail: drzoltan@icloud.com; Phone: 00852 (55) 844-379

${ }^{+}$Authors Zoltán Szabó and Diederik Venter contributed equally to this project and should be considered joint first authors
} 
tanil oxalate (usually $10 \mathrm{mg} / \mathrm{ml}$ ) make it very useful for remote delivery, but these factors increase the chance of accidental human intoxication (West et al., 2008). The effect of thiafentanil can be reversed with naltrexone (West et al., 2008).

Naltrexone is a competitive, pure opioid receptor antagonist at $\mu$ and $\kappa$ receptors, and to a lesser extent at $\delta$ receptors (Plumb, 2011; Taylor et al., 2013). In human medicine it is used in the management of opioid and alcohol dependence (Taylor et al., 2013). In veterinary medicine it is the antidote of choice for etorphine, carfentanil and thiafentanil. The advantage of naltrexone over naloxone is that it has a longer metabolic half-life, and thus renarcotisation is rarely a problem when naltrexone is used (Kreeger et al., 2002).

Azaperone is a neuroleptic sedative drug belonging to the butyrophenone class. It acts mainly as a dopamine antagonist but also has some antihistaminic and anticholinergic properties (Plumb, 2011). It is a common tranquiliser of choice in most anaesthetic drug combinations in wildlife medicine (Kreeger et al., 2002). It causes sedation and vasodilatation, decreases the heart rate, and can reduce the side effects of opioids by increasing the respiratory rate and suppressing vomiting (Wolfe et al., 2008). Interestingly, it can cause aggression in oryx (Kreeger et al., 2002).

Thiafentanil has been widely used for wildlife immobilisation on different species: nyala (Cooper et al., 2005), Lichtenstein's hartebeest (Citino et al., 2002), mule deer (Wolfe et al., 2004), emu (Cushing and McClean, 2010), Tibetan yak (Cushing et al., 2011), gaur (Napier et al., 2011), axis deer (Smith et al., 2006) and greater rhea (Ter Beest et al., 2012). The thiafentanil-azaperone combination for African buffalo (Syncerus caffer) immobilisation has been mentioned in books (Kreeger et al., 2002; West et al., 2008). The authors, however, could not find any peer-reviewed journal article about its usefulness on this species.

Thirty-four African buffaloes were successfully anaesthetised at Loskop Dam Nature Reserve, Mpumalanga, South Africa (S: $25^{\circ} 24^{\prime}$, E: $29^{\circ} 21^{\prime}$ ) on 23 July 2013. These animals belong to the largest subspecies of the African buffalo, the Cape buffalo (Syncerus caffer caffer). The animals were captured in the nature reserve and transported to bomas (boma is a South-African term to describe a fortified livestock enclosure or stockade) on the reserve, where they were housed in five groups of six to 11 animals, corresponding to the different herds from which they were captured.

The purpose of immobilisation in the boma was to provide opportunity for microchip implantation, morphometric measurements, photography, ear tag placement, intradermal tuberculin test and for blood sampling for foot and mouth disease, brucellosis (Brucella abortus) and corridor disease (Theileria parva) diagnosis. The estimated body weights of the animals were $600-900 \mathrm{~kg}$. Due to health and safety reasons, all animals within a boma were immobilised at the same time. The procedure took place in the early morning. The food was with- 
held for $24 \mathrm{~h}$ and water for $12 \mathrm{~h}$ to prevent regurgitation of the rumen contents and the development of rumen tympany as a result of the immobilisation.

Each buffalo was immobilised with thiafentanil oxalate (A3080, $10 \mathrm{mg} / \mathrm{ml}$ Wildlife Pharmaceuticals, White River, Mpumalanga, South Africa) at a dose of $6 \mathrm{mg} /$ animal (0.007-0.01 mg/kg) and azaperone (Stresnil, $40 \mathrm{mg} / \mathrm{ml}$, ScheringPlough Animal Health, Kenilworth, New Jersey, USA) at a dose of $40 \mathrm{mg} /$ animal $(0.07-0.04 \mathrm{mg} / \mathrm{kg}$ ) intramuscularly, using Dan-inject darts and gun (Dan Inject ApS, Børkop, Denmark).

After immobilisation, the animals were moved to sternal recumbency and their eyes were covered using blindfolds to decrease external visual stimulation and calm the animals (Mitchell et al., 2004; West et al., 2008).

Blood samples were taken from the jugular vein as soon as practical after immobilisation. Induction time was recorded as the time from darting until sternal or lateral recumbency was attained, and recovery time was the interval from receiving the reversal agent until the animal was able to maintain a standing posture. Palpebral and corneal reflexes, muscle tones as well as heart and respiratory rates were routinely monitored during the immobilisation, but only the respiratory rate was recorded in the case of 10 animals. Unfortunately, due to the number of animals immobilised at the same time, detailed monitoring using a pulse oximeter, ECG device capnograph or blood pressure meter was not possible.

The reversal agent naltrexone hydrochloride (Trexonil $50 \mathrm{mg} / \mathrm{ml}$, Wildlife Laboratories, Fort Collins, Colorado, USA) was given intravenously into the ear vein at a dose of $60 \mathrm{mg} /$ animal $(0.07-0.1 \mathrm{mg} / \mathrm{kg})$ after all the procedures on all the animals within a boma had been completed. The handling time, taken as the time between when the last animal within a boma reached recumbency and the time when the reversal agent was administered, was $17-25 \mathrm{~min}$. For safety reasons, all animals within a boma were reversed at the same time and the veterinary staff left the enclosure immediately.

To compare the induction and recovery times of male and female buffalos, resampling approximation of the $t$-test was performed using Resampling Stats Add-in for Excel (Statistics.com, Arlington, USA) and Microsoft Excel (Microsoft, Washington, U.S.) software.

The mean induction time of the buffaloes $(\mathrm{n}=34 ; 11$ males and $23 \mathrm{fe}-$ males) was $3.9 \pm 0.2 \mathrm{~min}$ (range: $3.5-4 \mathrm{~min}$ ) and the recovery time was $1.65 \pm$ $0.87 \mathrm{~min}$ (range: $1-4 \mathrm{~min}$ ). The induction and recovery times of female and male buffalos were not significantly different $(\mathrm{P}>0.05)$.

The respiratory rate was recorded in the case of 10 animals. The mean respiratory rate was $29.4 \pm 8.81 / \mathrm{min}$ (range: $14-48 / \mathrm{min}$ ).

Regardless of the fasting before the immobilisation, one female buffalo regurgitated a small amount of fluid during the procedure. The oral cavity of the animal was immediately cleaned to prevent aspiration of the rumen content. 
Apart from this, no adverse, short-term effects were detected after drug administration.

Our results suggest that thiafentanil immobilisation of African buffaloes in bomas is safe and effective. The immobilisation period was sufficient for blood sampling, morphometric measurements, photography, microchip implantation and ear tag placement. Unfortunately, due to the high number of animals immobilised at the same time, detailed monitoring (e.g. pulse oximetry, repeated blood sampling, recording heart rate and respiratory rate) was not possible.

The results of the present study indicate that thiafentanil oxalate, this lowvolume, high-potency, reversible drug combined with azaperone provides fast induction and smooth recovery. The authors recommend this drug combination as a reliable immobilising regimen for African buffaloes.

\section{Acknowledgements}

For their excellent work, we thank the veterinary interns Laura Pittenger and Tony Hall, the Conservation Medicine students and lecturers of Murdoch University: Linda-Jane Bowden, Rebekah Bruce, Petra Connell, Di Crispe, Ashton Hollwarth, Marek Misiewicz, Caroline Mynott, Emily Swan, Rachel Tidman, Tymon Yeo, Jordan Zec, Bec Donaldson, Lian Yeap, Scott McEwing and Kris Warren, and the team of the Loskop Dam Nature Reserve and the Mpumalanga Parks Board.

\section{References}

Citino, S. B., Bush, M., Grobler, D. and Lance, W. (2002): Anesthesia of boma-captured Lichtenstein's hartebeest (Sigmoceros lichtensteinii) with a combination of thiafentanil, medetomidine, and ketamine. J. Wildl. Dis. 38, 457-462.

Cooper, D. V., Grobler, D., Bush, M., Jessup, D. and Lance, W. (2005): Anaesthesia of nyala (Tragelaphus angasi) with a combination of thiafentanil (A3080), medetomidine and ketamine. J. S. Afr. Vet. Assoc. 76, 18-21.

Cushing, A. and McClean, M. (2010): Use of thiafentanil-medetomidine for the induction of anesthesia in emus (Dromaius novaehollandiae) within a wild animal park. J. Zoo Wildl. Med. 41, 234-241.

Cushing, A., McClean, M., Stanford, M., Lohe, T., Alcantar, B. E. and Chirife, A. D. (2011): Anesthesia of Tibetan yak (Bos grunniens) using thiafentanil-xylazine and carfentanilxylazine. J. Zoo Wildl. Med. 42, 713-717.

Kreeger, T. J., Arnemo, J. M. and Raath, J. P. (2002): Handbook of Wildlife Chemical Immobilization: International Edition. Wildlife Pharmaceuticals, White River, Mpumalanga, South Africa.

Mitchell, K. D., Stookey, J. M., Laturnas, D. K., Watts, J. M., Haley, D. B. and Huyde, T. (2004): The effects of blindfolding on behavior and heart rate in beef cattle during restraint. Appl. Anim. Behav. Sci. 85, 233-245.

Napier, J. E., Loskutoff, N. M., Simmons, L. G. and Armstrong, D. L. (2011): Comparison of carfentanil-xylazine and thiafentanil-medetomidine in electroejaculation of captive gaur (Bos gaurus). J. Zoo Wildl. Med. 42, 430-436. 
Plumb, D. C. (2011): Plumb's Veterinary Drug Handbook. Seventh edition. PharmaVet, Stockholm, Wis.

Smith, K. M., Powell, D. M., James, S. B., Calle, P. P., Moore, R. P., Zurawka, H. S., Goscilo, S. and Raphael, B. L. (2006): Anesthesia of male axis deer (Axis axis): evaluation of thiafentanil, medetomidine, and ketamine versus medetomidine and ketamine. J. Zoo Wildl. Med. 37, 513-517.

Taylor, R. Jr., Pergolizzi, J. V. Jr., Porreca, F. and Raffa, R. B. (2013): Opioid antagonists for pain. Expert Opin. Investig. Drugs 22, 517-525.

Ter Beest, J., McClean, M., Cushing, A. and Bildfell, R. (2012): Thiafentanil-dexmedetomidinetelazol anesthesia in greater rheas (Rhea americana). J. Zoo Wildl. Med. 43, 802-807.

West, G., Heard, D. and Caulkett, N. (2008): Zoo Animal and Wildlife Immobilization and Anesthesia. John Wiley \& Sons, Hoboken, NJ.

Wolfe, L. L., Goshorn, C. T. and Baruch-Mordo, S. (2008): Immobilization of black bears (Ursus americanus) with a combination of butorphanol, azaperone, and medetomidine. J. Wildl. Dis. 44, 748-752.

Wolfe, L. L., Lance, W. R. and Miller, M. W. (2004): Immobilization of mule deer with thiafentanil (A-3080) or thiafentanil plus xylazine. J. Wildl. Dis. 40, 282-287. 